\title{
Research on LRP Integration of E-Commerce Logistics under the Background of Integration of Collection and Distribution
}

\author{
Jiali Li, ${ }^{1,2}$ Zhijie Zhao, ${ }^{1}$ and Tao Cheng $\mathbb{1}^{1}$ \\ ${ }^{1}$ Northeast Asia Service Outsourcing Research Center, Harbin University of Commerce, Harbin 150028, Heilongjiang, China \\ ${ }^{2}$ College of Economics and Management, Heilongjiang Institute of Technology, Harbin 150050, Heilongjiang, China \\ Correspondence should be addressed to Tao Cheng; 6885854@qq.com
}

Received 23 August 2021; Revised 23 October 2021; Accepted 25 October 2021; Published 17 November 2021

Academic Editor: Daqing Gong

Copyright (c) 2021 Jiali Li et al. This is an open access article distributed under the Creative Commons Attribution License, which permits unrestricted use, distribution, and reproduction in any medium, provided the original work is properly cited.

\begin{abstract}
The distribution network composed of location and route is an important part of e-commerce logistics. With the continuous improvement of e-commerce requirements for logistics level, the practice of planning logistics network only from the perspective of the network location or the vehicle route can no longer meet the actual demand. In addition to the comprehensive consideration of the location-routing problem, the reverse logistics caused by customers' returning goods should be taken into account. In this paper, the destruction and reorganization strategy of adaptive large-scale neighborhood search algorithm was introduced into the traditional genetic algorithm, so as to conduct research on the logistics location-routing problem under the background of integration of collection and distribution. Finally, the effectiveness of the optimized genetic algorithm was verified by Matlab tools and the existing bench-marking data set of the location-routing problem, which provided reference for the planning and decision-making of logistics enterprises.
\end{abstract}

\section{Introduction}

As China's economic development enters new normalcy, since 2015, the development of China's e-commerce industry has gradually slowed down from ultrahigh speed, showing a steady growth trend, as shown in Table 1.

The continuous growth of e-commerce has brought unprecedented development opportunities to the logistics industry. Since 2015, the order volume of China's real-time logistics industry has continued to rise, as shown in Figure 1.

For logistics enterprises, the continuous expansion of market is both an opportunity and a challenge. E-commerce logistics involves many links, and there are many factors that affect logistics efficiency and cost. Research by Sureka et al. [1] (2018) shows that factors such as transportation process, accidents, product packaging, and storage have great impacts on logistics efficiency and results. Wang et al. [2] (2020) believe that economic development, location advantages, education level, and other factors have great impacts on regional logistics along the route. The research work of this paper will start from the perspective of the location of logistics distribution center and transportation vehicle route, under the background of the market demand of integration of collection and distribution, through optimizing the location-routing logistics network, to reduce logistics costs and improve logistics efficiency.

\section{Research Overview of Logistics Location- Vehicle Routing Integration}

2.1. Location Problem of Logistics. Logistics location problem usually refers to the location problem of logistics facilities, also called location allocation problem (LAP). As early as 1909, American logistics expert Weber [3] conducted research on the relationship of distribution distance between warehouses and multiple customers and logistics cost, which led many scholars to the research climax on the location of logistics centers. Therefore, the early single center location problem was also called single Weber problem, which meant finding a location in Euclidean space which could minimize the sum of the distances from several points representing customers to this location. When there is more than one 
TABLE 1: Development of e-commerce in China, 2015-2020.

\begin{tabular}{|c|c|c|c|c|c|c|}
\hline Year & $\begin{array}{c}\text { National } \\
\text { turnover } \\
\text { (trillion yuan) }\end{array}$ & $\begin{array}{l}\text { Online retail } \\
\text { sales (trillion } \\
\text { yuan) }\end{array}$ & $\begin{array}{l}\text { Rural online } \\
\text { retail sales } \\
\text { (trillion yuan) }\end{array}$ & $\begin{array}{l}\text { Total retail import and export of } \\
\text { cross-border e-commerce (100 } \\
\text { million yuan) }\end{array}$ & $\begin{array}{c}\text { Revenue scale of } \\
\text { e-commerce service } \\
\text { industry (trillion } \\
\text { yuan) }\end{array}$ & $\begin{array}{l}\text { E-commerce } \\
\text { employment scale } \\
(10,000 \text { personnel })\end{array}$ \\
\hline 2015 & 21.97 & 3.88 & 0.35 & 360.2 & 1.98 & 3255.32 \\
\hline 2016 & 26.10 & 5.16 & 0.89 & 499.6 & 2.45 & 3760.43 \\
\hline 2017 & 29.16 & 7.18 & 1.24 & 902.4 & 2.92 & 4250.32 \\
\hline 2018 & 31.63 & 9.01 & 1.37 & 1347.0 & 3.52 & 4700.65 \\
\hline 2019 & 34.81 & 10.63 & 1.70 & 1862.1 & 4.47 & 5125.65 \\
\hline 2020 & 37.21 & 11.76 & 1.79 & 2800.0 & 8.08 & 5535.70 \\
\hline
\end{tabular}

Source: China Cross-border E-commerce Development Report (2020), (Department of E-commerce and Information Technology, Ministry of Commerce). Note. Total retail import and export of cross-border e-commerce statistics refer to the total retail import and export volume of the customs cross-border e-commerce management platform.

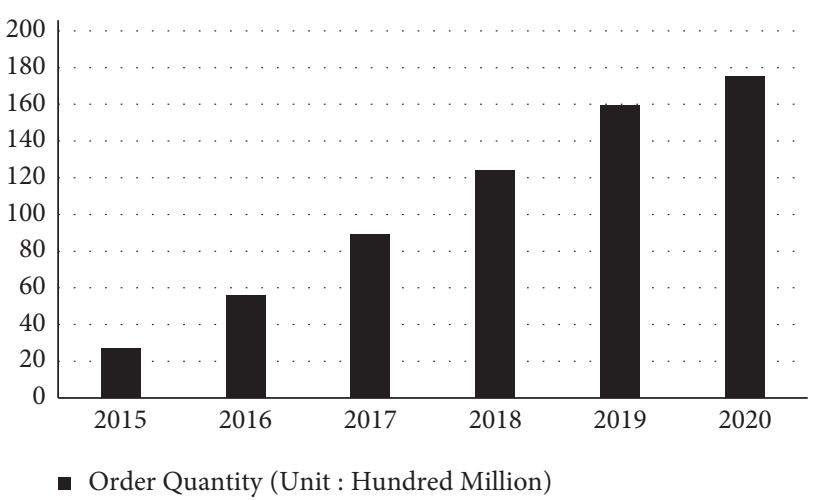

Figure 1: China's real-time logistics order volume from 2015 to 2020. Source: iResearch Institute.

such location, the problem transforms into a multi-Weber problem, also known as a P-median problem.

Assume that the number of facilities that need to be sited is $m$ and the number of customers with known location is $n$. The distribution capacity of each facility is $a_{i}$, and the demand of each customer is $b_{j} . F_{i}(i=1,2, \ldots, m)$ represents the $i^{\text {th }}$ facility, and $C_{j}(j=1,2, \ldots, n)$ represents the $j^{\text {th }}$ customer. $F_{i}=\left(x_{i}, y_{i}\right)$ is a decision variable that represents the unknown location of facility $i$, and $C_{j}=\left(u_{j}, v_{j}\right)$ represents the known location of customer $j$, as shown in Figure 2.

Two problems should be solved in the location of facilities. One is how to determine the locations of $m$ facilities, and the other is which customers each facility should be responsible for. Through location setting and task allocation, make sure that the sum of the distances between customers and the serving facilities is minimized. Namely,

$$
\min f(F, z)=\sum_{i=1}^{m} \sum_{j=1}^{n} t\left(F_{i}, C_{j}\right) \cdot z_{i j} .
$$

Assume that $g_{i}(z)$ is the total service demand of the customers served by the $i^{\text {th }}$ facility; the inequality needs to be met:

$$
\text { S.t. } g_{i}(z)=\sum_{j=1}^{n} b_{j} z_{i j} \leq a_{i}, \quad i=1,2, \ldots, m \text {. }
$$

This ensures that each facility has the ability to meet the customer's service demand. At the same time, it is also necessary to ensure that each customer is served by only one facility; namely,

$$
g_{m+j}(z)=\sum_{j=1}^{m} z_{i j}=1, \quad j=1,2, \ldots, n .
$$

Here, $z_{i j}$ is a decision variable with a value of 0 or 1 . $t\left(F_{i}, C_{j}\right)$ is the Euclidean distance from customer $j$ to facility $i$. Then, when the value of $z_{i j}$ is 1 ,

$$
t\left(F_{i}, C_{j}\right)=\sqrt{\left(x_{i}-u_{j}\right)^{2}+\left(y_{i}-v_{j}\right)^{2}} .
$$

Under the above ideas, many scholars have carried out relevant research work by using different methods. Tang [4] comprehensively considered factors such as transportation and land use, constructing a multilevel logistics center location model with the optimization goal of minimizing transportation costs. To improve efficiency and reduce costs, $\mathrm{Xu}$ et al. [5] used pseudo-reverse SMA to redesign the logistics distribution center location model. For cold chain logistics distribution, Xiao and Zhang [6] redesigned the location model by increasing the cost of goods loss target function, and the results showed that the single-level distribution network was the local optimal solution and the two-level distribution network was the overall optimal solution. Shu [7] improved the fuzzy comprehensive evaluation method and studied the location of the logistics center by using the multilevel fuzzy comprehensive evaluation method.

2.2. Vehicle Routing Problem. The vehicle routing problem (VRP) is the driving route problem, which was first proposed by Dantzig and Ramser [8]. In recent years, with continuous increase of demand for logistics industry from e-commerce, VRP has attracted more and more attention, and it has gradually become an important research subject in e-commerce logistics distribution. For a certain logistics enterprise, indexes such as the delivery point, the receiving point, the number and capacity limitation of the distribution vehicles, and the average daily distribution volume of goods 


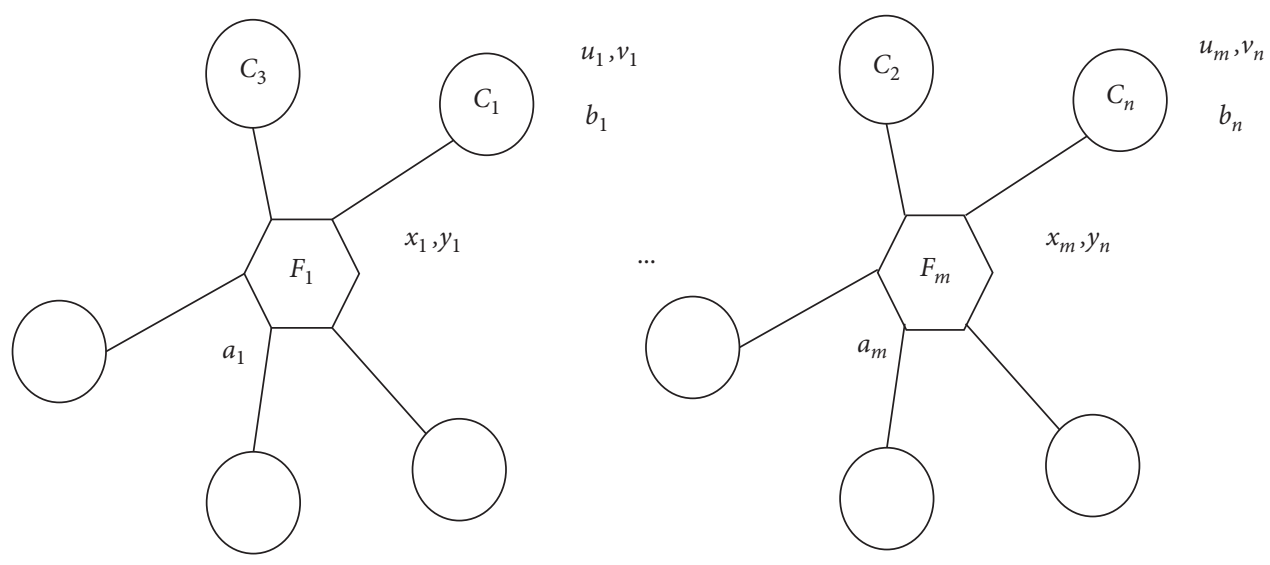

FIGURE 2: Schematic diagram of facilities-customer location service.

are relatively stable or are gradually adjusted according to the established plan, as shown in Figure 3.

In Figure $3, F_{i}(i=1,2, \ldots, m)$ represents the $i^{\text {th }}$ facility, and $C_{j}(j=1,2, \ldots, n)$ represents the $j^{\text {th }}$ customer. The distribution capacity of each facility is $a_{i}$, and the demand of each customer is $b_{j} . F_{i}=\left(x_{i}, y_{i}\right)$ represents the location of the $i$ facility, and $C_{j}=\left(u_{j}, v_{j}\right)$ represents the location of customer $j$. Each facility $F_{i}$ is responsible for providing distribution services to several customers $C_{j}$. Only one loop is set up for the driving route of the vehicle, and each customer point is only served once. In this case, the enterprise needs to scientifically plan the driving route of each vehicle in daily distribution process, thus achieving the goals of the shortest total mileage, the least time consumption, and the lowest distribution cost. $\mathrm{Xu}$ and $\mathrm{Yu}$ [9] used computer simulation technology to combine the user decision matrix with nonlinear functions to build a route planning model. $\mathrm{Ma}$ and Pan [10] built a logistics transportation routing optimization model based on the improved ant colony algorithm, which improved the transportation efficiency of the logistics industry. Xia and Zhou [11] took the transportation of canned fruit as an example and obtained the optimal route selection plan by establishing a mathematical model of linear planning. Pu and Zhang [12] used the improved ant colony algorithm to plan and design the routing problem of logistics and distribution vehicles, and the obtained optimal routing cost was much lower than that obtained by the traditional method.

\subsection{Problems of Integration of Collection and Distribution and} Location-Routing Integration. Maranzana [13], the founder of the research of the location-routing problem (LRP), was the first to study both the geographical location of the supply point and the sum of the distance from the supply point to the service point at the same time. Then, in more than 20 years, the research on LRP developed rapidly, and by the end of the 1980s, relevant research results reached a peak. In recent years, the rapid development of e-commerce has put forward higher requirements for logistics. The single research on distribution center location and transportation route can no longer meet the actual demand of logistics distribution. For this reason, the LRP has once again become the focus of research by a lot of scholars. The optimal logistics distribution network was realized by setting the facility location and the vehicle driving route at the same time, thereby realizing the optimal distribution plan. Scholars such as Wang et al. [14], Wang et al. [15], Guo et al. [16], and Liu et al. [17] have carried out research work on this issue.

Early LRP research was carried out aiming at logistics distribution, which mainly examined how to deliver goods to customers with the lowest cost and the highest efficiency. In 1992, the American Scholar Stock first proposed the concept of reverse logistics in a report submitted to the American Logistics Management Association, which has enlightened many scholars as to the study of the mathematical model, cost, value, efficiency, and other issues of reverse logistics.

Reverse logistics is actually the return receipt problem, also known as vehicle routing problem with backhauls (VRPB). With the continuous development of e-commerce industry, there have been more and more returns of goods, and the proportion of reverse logistics in the whole logistics has been gradually increasing. Therefore, when the logistics enterprises make distribution, they must consider the collection of goods as well, so that the study of e-commerce logistics optimization problems has become more and more complicated since it needs to combine the integration of collection and distribution and LRP issues together for consideration. In order to effectively solve this problem, this paper intends to design and develop new models and algorithms to carry out the following research work on the basis of previous research and analysis. When the model is built, fuzzy time window technology should be introduced to deal with the problem of greater elasticity of customer time satisfaction. In the design of the algorithm, the traditional adaptive genetic algorithm should be upgraded and improved by using the idea of destruction and reorganization of neighborhood search strategy, to further strengthen the algorithm solution ability, improve the convergence speed, and optimize the result. 


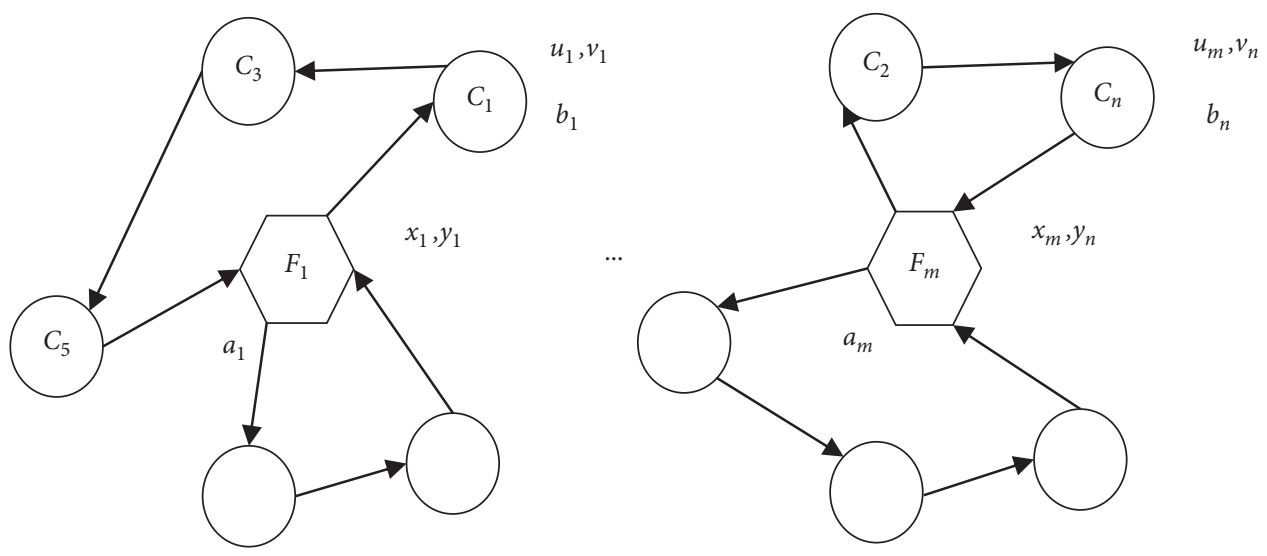

FIgURE 3: Schematic diagram of vehicle routing planning.

\section{Model and Algorithm Design}

\subsection{Model Construction}

3.1.1. Model Structure and Related Assumptions. A city's logistics network model usually consists of three levels, namely, distribution centers, transfer stations, and service outlets. The service outlets are also distribution-recycling outlets, which provide services directly to customers, as shown in Figure 4.

In the model shown in Figure 4, there are two-way logistics lines between different distribution centers. There are one-way logistics lines between the distribution centers and the transfer stations, and also between the transfer stations and the service outlets. In order to better complete the model design, we need to make the following assumptions.

First of all, the numbers and geographical locations of distribution centers, transfer stations, and service outlets are already known, and so are the service capacity and cost sharing of each level of network nodes. Second, the customers of each service outlet are already known, and so are the quantity of customer distribution and the goods accumulated. Third, the numbers of distribution vehicles between the three-level outlets are already known, and so is the total bearing capacity. Finally, the Euclidean distance between logistics network nodes is already known, and so is the driving distance of vehicles. Under the premise that the above assumptions are established, the first-level locationrouting analysis model is designed according to the structure diagram.

3.1.2. Building Mathematical Models. On the basis of the previous analysis, based on the demand of the research of location-routing under the premise of integration of collection and distribution, the mathematical model is constructed as follows:

(1) Total cost of logistics and distribution. $Z_{1}$ represents the total cost of logistics distribution, FD represents the apportioned cost of commodity, $Z_{K}(K=$ $\{1,2, \ldots, k\})$ represents the logistics cost of the $K^{\text {th }}$ commodity, RC represents the transportation cost per unit distance of the transportation vehicle, FV represents the fixed dispatch expenses of the transportation vehicle, and $d_{i j}$ represents the distance between nodes $i$ and $j . x_{i j k}$ is the decision variable, and when $x_{i j k}=1$, this means that the vehicle $K$ is driving from $i$ to $j$; when $x_{i j k}=0$, this means that there is no available route between $i$ and $j$. The minimum total logistics cost is

$$
\begin{aligned}
\operatorname{Min} Z_{1}= & \sum_{d \in N_{D}} \mathrm{FD} * Z_{K}+\sum_{i \in N} \sum_{j \in N} \sum_{k \in K} \mathrm{RC} * d_{i j} x_{i j k} \\
& +\sum_{i \in N} \sum_{j \in N} \sum_{k \in K} \mathrm{FV} * x_{i j k} .
\end{aligned}
$$

(2) Customer satisfaction level. Using $Z_{2}$ to represent customer satisfaction and $N_{c}=\{1,2, \ldots, c\}$ to represent the set of customer points of logistics network, the maximum customer satisfaction is

$\operatorname{Max} Z_{2}=\sum j \in N_{c} \frac{\left(S\left(T_{i}\right)+U_{j}\left(T_{j}\right)\right) *\left(d_{j}+p_{j}\right)}{\sum j \in N_{c}\left(d_{j}+p_{j}\right)}$.

(3) Restriction of integration of collection and distribution. Each vehicle is required to complete the customer's distribution and collection requirements at one time, which means that the standard of integration of collection and distribution must be satisfied. Meanwhile, it is also necessary to ensure that each customer can only be served by one vehicle.

$$
\begin{aligned}
\sum_{t \in n} \sum_{k \in K} x_{i j k} & =1, \quad \forall j \in J, \\
\sum_{j \in N} x_{i j k}-\sum_{j \in N} x_{j i k} & =0, \quad \forall i \in N, \forall k \in K .
\end{aligned}
$$

Here, $x_{i j k}$ is the decision variable; when $x_{i j k}=1$, this means that the vehicle $K$ is driving from $i$ to $j$; when $x_{i j k}=0$, this means that there is no available route between $i$ and $j$. 


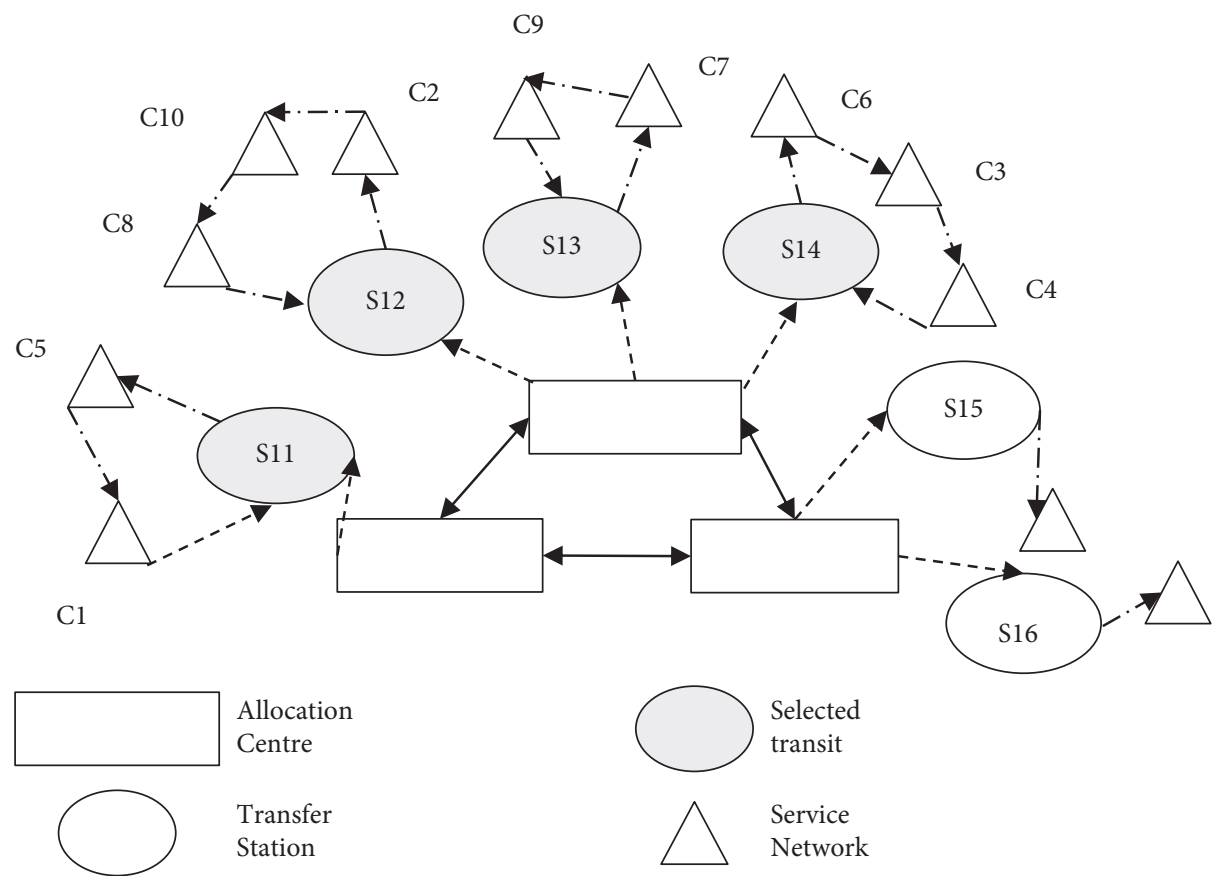

Figure 4: Single-level e-commerce logistics network model diagram.

(4) In order to ensure the level of customer satisfaction, customer service time needs to be constrained, and the constraint model is

$$
\begin{array}{ll}
\operatorname{Max}\left(\mathrm{AT}_{j}, \operatorname{Inf}\left(\lambda_{j}\right)\right) \leq T_{j} \leq \operatorname{Sup}\left(\lambda_{j}\right), & \forall j \in N_{c}, \\
\mathrm{AT}_{j}=\sum_{i \in v} x_{i j}\left(T_{i}+t_{i j}+t_{d} d_{i}+t_{p} p_{i}\right), & \forall j \in N_{c} .
\end{array}
$$

Here, $T_{j}$ represents the service time started by customer $i, \mathrm{AT}_{j}$ represents the time when the transportation vehicle reaches the location of customer $i, t_{p}$ represents the average collection time of unit goods, and $p_{i}$ represents the collection amount required by customer $i, i \in N_{c}$.

(5) The total amount of collected and distributed goods of the customers served by each transfer station cannot exceed the maximum capacity of the transfer station, and the constraint model is

$$
\begin{array}{ll}
\sum_{i \in N_{c}} d_{i} y_{i d} \leq \mathrm{CD} z_{d}, & \forall d \in N_{D}, \\
\sum_{i \in N_{c}} p_{i} y_{i d} \leq \mathrm{CD} z_{d}, & \forall d \in N_{D} .
\end{array}
$$

Here, CD represents the service capacity limit of the distribution center, and $N_{D}=\{i \mid i=1,2, \ldots, m\}$ is the set of transfer stations in the distribution system. $z_{d}$ is a decision variable, and when its value is 1 , this means that the distribution center point $d$ is selected; otherwise it is not selected.

(6) The total bearing capacity of the assigned vehicles in each distribution route must be greater than the total amount of goods collected and distributed in that route, and the constraint model is

$$
U_{i j}+V_{i j} \leq C V_{i j}, \quad \forall i, j \in N, i \neq j .
$$

(7) The customer and the transfer station, and the vehicle and the transfer station are restricted to one-toone relationship. At the same time, during the driving process, the loop between the customer points should be avoided. The constraint model is

$$
\begin{gathered}
\sum_{k \in N_{D}} y_{i k}=1, \quad \forall i \in N_{c}, \\
\sum_{p \in N_{c}} x_{i p k}+\sum_{p \in N, p \neq j} x_{p j k} \leq 1+y_{i d}, \quad \forall i \in N_{c}, \forall d \in N_{D}, \forall k \in K, \\
u_{i}-u_{j}+N \sum_{k \in K} x_{i j k} \leq N-1, \quad \forall i \in N_{c}, \forall j \in N_{c} .
\end{gathered}
$$


(8) In the distribution process, the upper limit of the collection and delivery quantity of each participating customer's transfer station is fixed. Therefore, it is necessary to ensure that the total collection and delivery volume of the transfer station remains conserved. The constraint model is

$$
\begin{aligned}
& \sum_{j \in N_{c}} U_{k j}=\sum_{j \in N_{c}} d_{j} y_{j d}, \quad \forall d \in N_{D}, \\
& \sum_{j \in N_{c}} V_{j k}=\sum_{j \in N_{c}} p_{j} y_{d j}, \quad \forall d \in N_{D}, \\
& \sum_{j \in N_{c}} U_{k j}=0, \quad \forall k \in N_{D}, \\
& \sum_{j \in N_{c}} V_{j k}=\sum_{j \in N_{c}} p_{j} y_{d j}, \quad \forall d \in N_{D} .
\end{aligned}
$$

3.2. Algorithm Design. The location-routing integration problem is a combination of the site-path problem and the path problem, and its complexity is equivalent to the superposition of the latter two. When the logistics network covers a wide area and the scale of operations is large, it is almost impossible to use exact algorithms to study the location-routing integration problem. For example, in the description of customer delivery time requirements, we have different criteria and principles for assigning time windows to each customer, so the use of fuzzy time windows is the correct choice. In the algorithm design, the destruction and reorganization strategy for nodes in the adaptive large-scale neighborhood search algorithm is introduced into the hybrid adaptive genetic algorithm to improve the various approach of the traditional adaptive algorithm and increase the efficiency and convergence speed of the algorithm solution. The specific computation can be carried out in two stages. In the first stage, the target problem is transformed into a location path problem with hard time window constraints and solved to obtain a relatively optimal solution for logistics costs; in the second stage, the optimal solution obtained in the first stage is computed again using a fuzzy optimization procedure, which is shifted forward or backward on the basis of removing the solidified path to further improve the level of customer satisfaction.

\subsubsection{Large-Scale Neighborhood Search Strategy and Hybrid} Adaptive Genetic Algorithm. The adaptive large-scale neighborhood search algorithm is a heuristic method proposed by Ropke and Pisinger in 2006. The nature of the neighborhood search algorithm is to destroy and repair the initial solution alternately and finally obtain the optimal solution. The measurement of the effect of operators is added by ALNS on the basis of neighborhood search, so that the algorithm can automatically select a more suitable operator to destroy and repair the initial solution. In this way, the probability of obtaining a better solution can be greatly improved. There are many algorithms that can be used for neighborhood search, among which the simulated annealing algorithm has the problem that it can only use one neighborhood, so the space that can be searched is relatively small, and so is the probability of finding the globally optimal solution. The variable neighborhood search algorithm, with a large search range, can be used to find the optimal solution from multiple neighborhoods. However, since this algorithm lacks necessary goals, blind search often happens. Relatively speaking, the adaptive large-scale neighborhood search algorithm makes up for the above shortcomings. When making neighborhood selection, it can make judgments according to the historical operation results, which greatly increases the probability of obtaining the optimal solution.

For logistics networks, the destruction process is the removal of service outlets, distribution routes, transit stations, or distribution centers one by one, and the removal objects are temporarily stored in an Insert array. After the destruction, the repair process is carried out, with the objects in the Insert array being randomly inserted into the insertable locations and the cost being recalculated. Finally a local search is performed until an optimal solution is found.

The destruction and repair strategy of large-scale neighborhood search algorithm is introduced into the hybrid adaptive genetic algorithm to replace the original crossover and mutation process and complete the algorithm optimization. The specific process is shown in Figure 5.

\subsubsection{Coding and Penalty Function Design. Take Figure 4 as} an example; natural numbers are used for encoding which consists of three parts. The first part is the customer sequence number. There are 10 customer points needing logistics services, with the serial numbers $\mathrm{C} 1 \sim \mathrm{C} 10$. The second part is the vehicle code. There are 6 transportation vehicles with the serial numbers V1 V6. The vehicle code is represented by the code of the customer initially served by the vehicle. The third part is the transfer station code. In this example, there are 6 transfer stations with the serial numbers S11 S16. Among them S11, S12, S13, and S14 are selected, and the unselected transfer stations and vehicle codes are occupied with 0 . According to the above rules, the codes generated are $[1,5,8,10,2,9,7,6,3,4,5,2,7,6,0,0,11,12$, $14,14,0,0]$. This code is divided into three substrings, as shown in Figure 6.

The four selected transfer stations generate four vehicle transportation routes, namely, Route 1: 11-5-1-11; Route 2: 12-2-10-8-12; Route 3: 13-7-9-2-13; and Route 4: 14-6-3-14.

$P_{1}$ represents the penalty for exceeding the upper limit of the vehicle bearing capacity, $P_{2}$ represents the penalty for exceeding the maximum visual waiting line of the customer, and $P_{3}$ represents the penalty for exceeding the maximum service capacity of the transfer station. According to the algorithm design requirements, the penalty constraint functions are shown in the following formulas: 


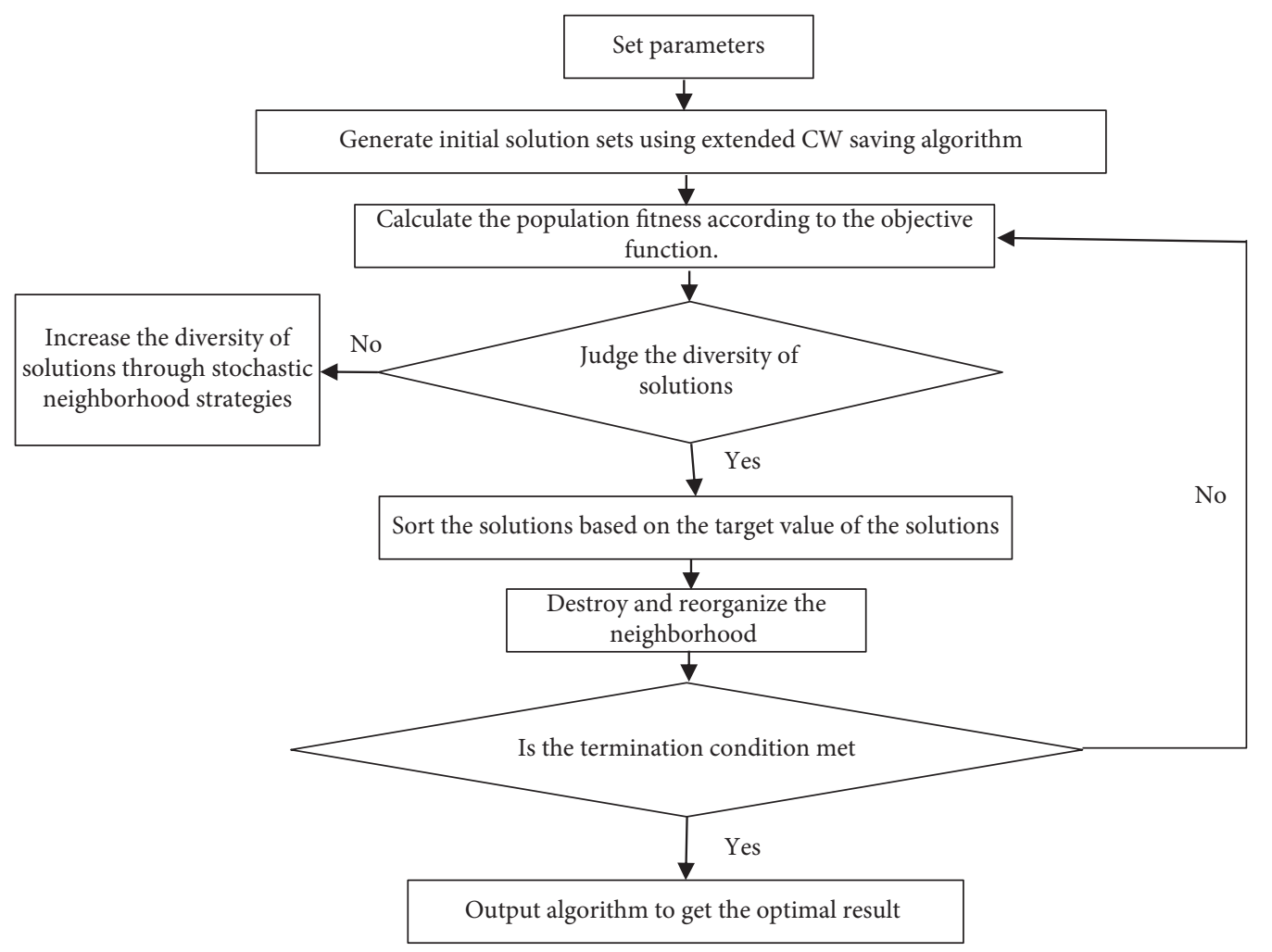

FIgURE 5: Optimized adaptive genetic algorithm solution process.

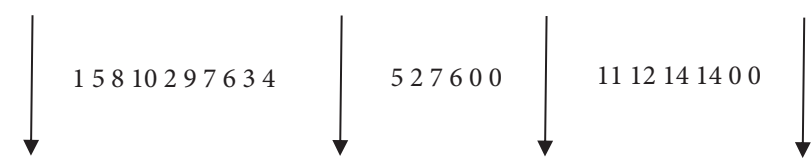

Figure 6: Example of natural number coding of LRP solutions.

$$
\begin{aligned}
& P_{1}=\sum_{i \in N_{d}} \sum_{j \in N_{c}} \operatorname{Max}\left(U_{i j}+V_{i j}-\mathrm{CV}_{k} x_{i j k}, 0\right), \\
& P_{2}=\sum_{j \in N c} \operatorname{Max}\left(\operatorname{Inf}\left(\lambda_{j}\right)-\mathrm{AT}_{j}, 0\right)+\sum_{j \in N c} \operatorname{Max}\left(\mathrm{AT}_{j}-\operatorname{Sup}\left(\lambda_{j}\right), 0\right), \\
& P_{3}=\sum_{i \in N_{d}} \operatorname{Max}\left(\sum_{j \in N_{c}} d_{j} z_{i j}-C D_{i} z_{i}, 0\right)+\sum_{i \in N_{d}} \operatorname{Max}\left(\sum_{j \in N_{c}} P_{j} z_{i j}-C D_{i} z_{i}, 0\right) .
\end{aligned}
$$

3.2.3. Generation of Initial Solutions. $\mathrm{EF}_{j}$ represents the amount of time change of the vehicle from $i$ to $j$, and there are

$$
\mathrm{EF}_{j}=T_{i}+t_{i j}+t_{d} d_{i}+t_{p} p_{i}-T_{j}
$$

$\Delta_{j-}$ represents the maximum allowed amount of time forward between $j$ and the customer point behind it, and there are

$$
\Delta_{j-}=\operatorname{Min}_{r \geq j}\left\{T_{r}-\mathrm{ET}_{r}\right\}
$$

$\Delta_{j+}$ represents the maximum allowed amount of time backward between $j$ and the customer point behind it, and there are

$$
\Delta_{j+}=\operatorname{Min}_{r \geq j}\left\{\mathrm{LT}_{r}-\mathrm{ET}_{r}\right\}
$$

The specific process is as follows:

(1) Scan the unassigned customer points one by one, connect the customer points with the nearest transfer stations, and count them into the relationship set. 
TABLE 2: Comparison of result sets of different algorithms.

\begin{tabular}{|c|c|c|c|c|c|c|}
\hline Serial no. & Barreto example & The algorithm in this paper & SA-ACS algorithm & GRASP algorithm & $\mathrm{CH}$ algorithm & $\begin{array}{l}\text { Optimal } \\
\text { solution }\end{array}$ \\
\hline 1 & Gaskell67-21 * 5 & 425 & 430 & 425 & 436 & 425 \\
\hline 2 & Gaskell67-22 * 5 & 585 & 587 & 585 & 592 & 585 \\
\hline 3 & Gaskell67-30 * 5 & 565 & 564 & 567 & 567 & 557 \\
\hline 4 & Gaskell67-34 * 5 & 467 & 462 & 462 & 463 & 452 \\
\hline 5 & Christofides69-50 * 5 & 576 & - & 599 & 583 & 566 \\
\hline 6 & Christofides $69-100 * 10$ & 869 & - & 862 & 889 & 838 \\
\hline 7 & Perl83-50-10 & 1019 & 1021 & - & 1039 & 1015 \\
\hline 8 & Perl83-80 * 7 & 1616 & 1606 & - & 1611 & 1578 \\
\hline 9 & Min92-125*8 & 5789 & 6109 & 5868 & 6138 & 5609 \\
\hline 10 & Daskin95-150 $* 10$ & 45655 & - & - & 46643 & 43920 \\
\hline
\end{tabular}

TABLE 3: Efficiency and stability.

\begin{tabular}{|c|c|c|c|c|c|c|}
\hline Serial no. & Barreto example & $\begin{array}{l}\text { Algorithm optimal } \\
\text { solution }\end{array}$ & Average & $\begin{array}{c}\text { Convergence } \\
\text { numbers }\end{array}$ & Proportion of optimal solution & Deviation rate (\%) \\
\hline 1 & Gaskell67-21 * 5 & 425 & 435.5 & 7 & 0.44 & 3 \\
\hline 2 & Gaskell67-22 * 5 & 585 & 591.8 & 6 & 0.41 & 1 \\
\hline 3 & Gaskell67-30 * 5 & 565 & 576.3 & 6 & 0.38 & 2 \\
\hline 4 & Gaskell67-34 * 5 & 467 & 518.3 & 6 & 0.38 & 11 \\
\hline 5 & Christofides $69-50 * 5$ & 576 & 582.7 & 6 & 0.40 & 3 \\
\hline 6 & $\begin{array}{l}\text { Christofides69- } \\
100 * 10\end{array}$ & 869 & 906.4 & 5 & 0.31 & 8 \\
\hline 7 & Perl83-50-10 & 1019 & 1049.5 & 6 & 0.35 & 3 \\
\hline 8 & Perl83-80 * 7 & 1616 & 1664.5 & 5 & 0.31 & 3 \\
\hline 9 & Min92-125 * 8 & 5789 & 6252.1 & 5 & 0.30 & 9 \\
\hline 10 & Daskin95-150 $* 10$ & 45655 & 46642.7 & 6 & 0.43 & 6 \\
\hline
\end{tabular}

(2) According to the quantity of customers, sort the transfer stations, set the top transfer station as selected mode, and arrange the vehicles.

(3) According to the principle of the shortest distance priority, sort the customers of the selected transfer station, and calculate the distance cost sort table between the transfer station and each customer one by one.

(4) Connect with customers one by one according to the distance cost sort table, and judge whether the current vehicle capacity is met. If not, skip to step (7); if met, skip to step (6).

(5) Calculate $\mathrm{EF}_{j}$, and if $\mathrm{EF}_{j}=0$, perform step (6). If $\mathrm{EF}_{j} \neq 0$, calculate the $\Delta_{j-}$ and $\Delta_{j+}$; if $\left|\mathrm{EF}_{j}\right|<\Delta_{j_{-}}$or $\left|\mathrm{EF}_{j}\right|<\Delta_{j+}$, perform step (6); otherwise skip to step (7).

(6) Add the customer pair to the end of the current route set and recalculate the time when the vehicle reaches the locations of each customer.

(7) Remove the current customer pair from the distance cost sort table and skip to step (4).

\section{Validity Verification}

4.1. Validity Verification of Algorithm. A Ph.D. thesis from the University of Aveiro in Barreto [18] has compiled a set of bench-marking data for location-routing problems with multiple constraints. This paper intends to use this data set to verify the algorithm designed above and illustrate the effectiveness of this algorithm through comparative analysis with other common algorithms.

In order to get valid parameters as far as possible, before the formal operation, we need to perform multiple trial operations to fine-tune the parameters according to the results of the operations. The operation parameters mainly include the following:

Different population size parameters: $N$.

Termination of evolution parameters: MAXGEN.

Probability of removing adjacent point parameter: $\mathrm{RP}_{1}$.

Probability of removing maximum saving point parameter: $\mathrm{RP}_{2}$.

Probability of removing random route parameter: $\mathrm{RP}_{3}$. Probability of removing single point route parameter: $\mathrm{RP}_{4}$.

Probability of closing and opening distribution outlets parameter: $\mathrm{RP}_{5}$.

Not-allowed-to-change distribution network status parameter: $g_{\max }$.

The data analysis and algorithm operation environment adopts Matlab, a tool produced by the MathWorks. The core logic of the algorithm is mainly written by $\mathrm{C \#}$ tool. The algorithm function of C\# class library needs to be transferred 
TABLE 4: Transit station information.

\begin{tabular}{lcccc}
\hline Serial number & \multicolumn{2}{c}{ Coordinate } & Maximum service volume & Apportioned fixed value \\
\hline 1 & $X$ & $Y$ & 140 & 10.8 \\
2 & 5 & 8 & 140 & 11.9 \\
3 & 35 & 6 & 140 & 6.1 \\
4 & 37 & 23 & 140 & 7.6 \\
5 & 19 & 44 & 140 & 7.5 \\
\hline
\end{tabular}

TABLE 5: Customer point information.

\begin{tabular}{|c|c|c|c|c|c|}
\hline \multirow{2}{*}{ Serial number } & \multicolumn{2}{|c|}{ Coordinate } & \multirow{2}{*}{ Delivery volume } & \multirow{2}{*}{ Pick-up quantity } & \multirow{2}{*}{ Time window } \\
\hline & $X$ & $Y$ & & & \\
\hline 1 & 20 & 35 & 17 & 20 & {$[0,45,119,169]$} \\
\hline 2 & 8 & 31 & 18 & 15 & {$[0,20,115,165]$} \\
\hline 3 & 29 & 43 & 13 & 16 & {$[0,41,114,174]$} \\
\hline 4 & 18 & 39 & 19 & 13 & {$[0,41,100,150]$} \\
\hline 5 & 19 & 47 & 12 & 16 & {$[0,16,69,129]$} \\
\hline 6 & 31 & 24 & 18 & 14 & {$[0,30,90,140]$} \\
\hline 7 & 38 & 50 & 13 & 15 & {$[0,18,119,169]$} \\
\hline 8 & 33 & 21 & 13 & 6 & {$[0,38,120,170]$} \\
\hline 9 & 2 & 27 & 17 & 19 & {$[0,9,81,141]$} \\
\hline 10 & 1 & 12 & 20 & 16 & {$[0,4,81,131]$} \\
\hline 11 & 26 & 20 & 16 & 22 & {$[0,21,89,149]$} \\
\hline 12 & 20 & 33 & 18 & 15 & {$[0,8,86,136]$} \\
\hline 13 & 15 & 46 & 15 & 19 & {$[0,18,73,133]$} \\
\hline 14 & 17 & 19 & 11 & 8 & {$[0,46,138,188]$} \\
\hline 15 & 20 & 26 & 18 & 25 & {$[0,17,112,172]$} \\
\hline 16 & 15 & 12 & 16 & 12 & {$[0,28,106,156]$} \\
\hline 17 & 5 & 30 & 15 & 20 & {$[0,32,111,171]$} \\
\hline 18 & 13 & 14 & 15 & 12 & {$[0,9,84,144]$} \\
\hline 19 & 38 & 5 & 15 & 18 & {$[0,36,132,192]$} \\
\hline 20 & 9 & 40 & 16 & 13 & {$[0,22,72,132]$} \\
\hline
\end{tabular}

TABLE 6: Other parameters.

\begin{tabular}{lccc}
\hline FV & 1000 & $\mathrm{EDT}_{i}$ & Unif $[0,50]$ \\
\hline RC & 100 & $\mathrm{ET}_{i}$ & $\left.\mathrm{Max}_{2} \mathrm{EDT}_{i}-50\right\}$ \\
CV & 70 & $\mathrm{LDT}_{i}$ & $\mathrm{Unnif}\left[\mathrm{EDT}_{i}+* 50, \mathrm{EDT}_{i}+100\right]$ \\
$\lambda$ & {$[0.6,0.7,0.8,0.9,1]$} & $\mathrm{LT}_{i}$ & $\mathrm{LDT}_{i}+50$ \\
\hline
\end{tabular}

into Matlab; by combining the built-in functions of Matlab toolbox, we can finish the solution process of the calculating set of the standard provided by Barreto and get the result set. Since the calculating set of the data set is massive, we only select ten representative sets of data for operation. In order to effectively measure the advantages and disadvantages of this result set, we have compared it with the result sets of different algorithms in other literature, which include GRASP algorithm, CH algorithm, and SA-ACS algorithm, as shown in Tables 2 and 3.

As seen in the tables, the algorithm in this example does not rule out the possibility of a sudden change in probability in the solution process, which means that the solution of some smaller problems may take a lot of time, or even there is no globally optimal solution found within the time range set by the system. On the contrary, for some largescale problems, we can find their globally optimal solution in a very short time. The existence of this mutation probability lays hidden dangers for the fairness of the algorithm. Nevertheless, by comparing the algorithm of this paper with the other three types of algorithms and known optimal solutions, we can see that the indexes of the designed algorithm perform pretty well. In the two examples of Gaskell67-21 *5 and Gaskell67-22*5, the solutions obtained by the algorithm in this paper were completely consistent with the optimal solutions. The deviation rate fluctuated between $1 \%$ and $11 \%$, while the example Gaskell67-34 * 5 had the highest 6-time convergence deviation rate, which reached $11 \%$, and the deviation rates of the other 9 examples were below 10\%, which was quite reasonable generally. The above data fully shows that the algorithm designed in this paper can be applied in solving actual problems, and it can offer reference for logistics enterprises to make decisions. 
TABLE 7: Solving optimization results.

\begin{tabular}{|c|c|c|c|c|c|c|}
\hline Total cost & $\begin{array}{c}\text { Distribution } \\
\text { cost }\end{array}$ & Fixed cost sharing & Enabled transit station & Number of vehicles enabled & $\begin{array}{l}\text { Minimum } \\
\text { satisfaction }\end{array}$ & $\begin{array}{c}\text { Optimization } \\
\text { satisfaction }\end{array}$ \\
\hline 36371.4 & 36789 & 31.5 & S11, S12, S13, S14 & 4 & 0.9 & 0.918 \\
\hline
\end{tabular}

4.2. Validation of the Model. Because there is no standard example, this paper uses the bench-marking example 20-5-1a proposed by Prins [19] in 2006 to verify the effectiveness of the model. The parameter information is shown in Tables 4-6.

In the model designed in this paper, four transfer stations and four transport vehicles are enabled, and four distribution routes are set as follows: Route 1: 11-5-1-11; Route 2: 12-2-10-8-12; Route 3: 13-7-9-2-13; and Route 4: 14-6-3-14. The minimum customer satisfaction is set at 0.9, and the optimization solution is carried out by using the example data from Tables 4-6. The results are shown in Table 7.

It can be seen from Tables 4-6 that, after optimization, the customer satisfaction increased from 0.9 to 0.918 , an increase of $2 \%$. Therefore, the model designed in this paper is correct and feasible, which can provide guidance for logistics enterprises' location path planning decision.

\section{Research Conclusions}

The vigorous development of e-commerce has brought unprecedented development opportunities to logistics enterprises, but meanwhile it also puts forward higher requirements for the quality of logistics services. For logistics enterprises, reducing distribution costs and improving distribution efficiency are not only the needs for the enterprise's own development, but also the inevitable requirements to meet social needs and improve customer satisfaction. Through scientific planning, the logistics location-routing problem can be effectively solved, and the above goals of enterprises can be achieved.

Firstly, this paper briefly analyzed the development and research status of location-routing problem and suggested that, for modern logistics enterprises, a single location selection and planning could no longer meet the development requirements; instead, we should solve location-routing problem intensively. In addition, the paper expounded the research and development status of location-logistics under the background of integration of collection and distribution. Next, by using the research strategy of adaptive large-scale neighborhood search algorithm for reference, the paper embedded the destruction and reorganization method in the traditional genetic algorithm to replace the original crossfactor and variation factor link, thus realizing the design of the analysis model and algorithm.

Finally, the bench-marking data set of the locationrouting problem with multiple constraints sorted out by Barreto was used in this paper, and the Matlab tools were used to verify the effectiveness of the designed model and algorithm. Compared with the known optimal solution, the calculation result sets of the optimization algorithm designed in this paper were all within the confidence interval, and the deviation rates were basically around $10 \%$, indicating that the algorithm had good availability and could be applied to analyze and deal with practical problems and provide reference for the planning and decision-making of logistics enterprises.

\section{Data Availability}

The data of this study are mainly from the annual statistical yearbook of the National Bureau of Statistics of China and the annual e-commerce reports of the National E-commerce Public Service Network of the Ministry of Commerce of China. The following are relevant links: https://data.stats. gov.cn/; https://dzswgf.mofcom.gov.cn/yjbg/page1.html.

\section{Conflicts of Interest}

The authors declare that they have no conflicts of interest.

\section{Acknowledgments}

The paper is financially supported by National Social Science Fund project (19BJY153); Heilongjiang Province Philosophy and Social Science Research Planning Projects (20GLH030, 18JYB145); Heilongjiang Institute of Technology Innovation Team Fund Project (2020CX08); Heilongjiang Institute of Technology PhD Startup Fund Project (2017BJ01, 2019DS027): The impact of e-commerce on the development of green food industry in Heilongjiang province.

\section{References}

[1] G. Sureka, Y. Mahinda, and D. Wickramarachchi, "Factors affecting the efficiency and effectiveness of reverse logistics process," Journal of International Logistics and Trade, vol. 16, no. 2, pp. 74-87, 2018.

[2] H. Wang, Q. Tian, J. Li, and X. Li, "Stochastic frontier analysis of logistics efficiency and its influencing factors in provinces along the "belt and road", Journal of Highway and Transportation Research and Development, vol. 37, no. 10, pp. 151-158, 2020.

[3] A. Weber, Uber den Standort der Industrien, University of Chicago, Chicago, IL, USA, 1929.

[4] Z. Tang, "Multi-level logistics center location based on harmony search algorithm," Logistics Technology, vol. 38, no. 11, pp. 89-92, 2019.

[5] X. Xu, Z. Yang, and L. Liu, "SMA for solving the location problem of logistics distribution center," Computer Engineering and Applications, vol. 56, no. 1, pp. 150-157, 2020.

[6] Z. Xiao and X. Zhang, "The location model of cold chain logistics distribution center that meets the JUSDA limitations," Statistics \& Decisions, vol. 36, no. 12, pp. 185-188, 2020.

[7] X. Shu, "Analysis on the location of logistics center based on fuzzy comprehensive evaluation method," Neijiang Science and Technology, vol. 42, no. 3, pp. 43-44, 2021.

[8] G. B. Dantzig and J. H. Ramser, "The truck dispatching problem," Management Science, vol. 6, no. 1, pp. 80-91, 1959. 
[9] C. Xu and X. Yu, "Modeling and simulation analysis of optimal choice of transportation route for intelligent transportation platform," Computer Simulation, vol. 36, no. 3, pp. 175-178, 2019.

[10] G. Ma and F. Pan, "Research on logistics transportation route based on improved ant colony algorithm," Computer Engineering and Science, vol. 42, no. 3, pp. 523-528, 2020.

[11] Q. Xia and J. Zhou, "Research on optimization of transportation route based on MATLAB software," Logistics Technology, vol. 43, no. 10, pp. 97-100, 2020.

[12] M. Pu and Y. Zhang, "Optimization method of logistics distribution vehicle route based on improved ant colony algorithm," Journal of Jilin Institute of Chemical Technology, vol. 38, no. 5, pp. 90-94, 2021.

[13] F. E. Maranzana, "On the location of supply points to minimize transport costs," Journal of the Operational Research Society, vol. 15, no. 3, pp. 261-270, 1964.

[14] S. Wang, Y. Zhao, L. Leng, C. Zhang, and H. Jiang, "Lowcarbon location-routing problem based on ant colony selection hyper-heuristic algorithm," Computer Integrated Manufacturing Systems, vol. 26, no. 6, pp. 1702-1716, 2020.

[15] C. Wang, Y. Zheng, H. Yilong, and H. Hongtao, "Research on location selection of fresh food logistics distribution networkroute optimization," Mathematics in Practice and Knowledge, vol. 50, no. 10, pp. 33-43, 2020.

[16] F. Guo, Z. Huang, and W. Huang, "Research on delivery vehicle routing problem while considering the location and service strategy of the front warehouse," System Engineering Theory and Practice, vol. 41, no. 4, pp. 962-978, 2021.

[17] D. Liu, H. Zhang, and L. Zhang, "Simultaneous delivery and pickup location-routing problem and hybrid immune algorithm," Application Research of Computers, vol. 1-7, 2021.

[18] S. S. Barreto, "Analysis and modeling of location-routing problems," Ph.D. Thesis, University of Averiro, Aveiro, Portugal, 2004.

[19] C. Prins, C. Prodhon, and R. W. Calvo, "Solving the capacitated location-routing problem by a GRASP complemented by a learning process and a path relinking," $4 O R$, vol. 4, no. 3, pp. 221-238, 2006. 